\title{
The dopamine withdrawal test following surgery for intracranial aneurysms
}

\author{
AD MENDELOW, S DHARKER, J PATTERSON, F NATH, GM TEASDALE \\ From the Department of Neurosurgery, Institute of Neurological Sciences, Glasgow, Scotland
}

SUMMARY Cerebral blood flow was measured in eight patients who were being treated with dopamine in order to maintain cerebral perfusion after the onset of delayed postoperative ischaemia following intracranial aneurysm surgery. Measurements were made whilst on treatment and repeated either during a reduction in the dosage or withdrawal of dopamine. There was a significant fall in cerebral blood flow in both hemispheres in all eight patients. Clinical deterioration was observed in seven of nine instances in which cerebral blood flow fell by $25 \%$ or more of the value while on dopamine treatment. There were no episodes of deterioration in six tests where the fall in cerebral blood flow was less than $25 \%$ of the starting value. It is suggested that cerebral blood flow measurement can be useful in predicting when it is safe to withdraw dopamine treatment in these patients. Hypertensive treatment should be maintained if a withdrawal test is associated with a fall in cerebral blood flow of $25 \%$ or more.

With the resurgence of interest in earlier surgery for patients with ruptured intracranial aneurysms, there is an increased incidence of cerebral ischaemia several hours or days after operation. In an attempt to prevent or treat the intracranial arterial spasm thought to underly such deterioration, many different substances have been tried.' It is increasingly realised that clinical deterioration may be the result of a relative fall in cerebral perfusion pressure (CPP) and successful reversal of ischaemic deficits has been reported with elevation of CPP either with hypervolaemic treatment ${ }^{2}$ or with pharmacologically induced hypertension. ${ }^{3}$ Hypertensive treatment may need to be continued for many days, and premature withdrawal may precipitate a further episode of clinical deterioration, either immediately or after a delay. The aim of the present study was to determine if measurements of cerebral blood flow could be used to predict deterioration following withdrawal of hypertensive treatment, and to evaluate its usefulness as a guide to the timing of its cessation.

\section{Patients and methods}

We report eight patients who had suffered a subarachnoid

Address for reprint requests: Mr AD Mendelow, Department of Neurosurgery, Institute of Neurological Sciences, Southern General Hospital, Govan Road, Glasgow G51 4TF, Scotland.

Received 12 February 1985 and in revised form 22 May 1985. Accepted 28 May 1985 haemorrhage from rupture of an intracranial aneurysm. In each case, the aneurysm had been clipped, and the patient had been fully orientated with no focal neurological deficit immediately before and after operation. Delayed postoperative ischaemia was diagnosed clinically when focal neurological signs developed or when there was deterioration in the level of consciousness; in these patients its clinical onset was diagnosed from one to six days after operation. Hypertensive treatment was instituted with dopamine ( $800 \mathrm{mg}$ in $500 \mathrm{ml}$ of saline) infused via a central line at a rate of $5 \mathrm{ml}$ per hour, increasing the infusion by $5 \mathrm{ml}$ per hour every 5 minutes until the systolic blood pressure reached $180 \mathrm{~mm} \mathrm{Hg}$. The lowest dose of dopamine required to maintain a systolic blood pressure close to 180 $\mathrm{mm} \mathrm{Hg}$ was used. The dosage tended to rise with the passage of time as a manifestation of tachyphylaxis, but the maximum dose used was $70 \mathrm{ml}$ per hour $(30 \mu \mathrm{g} / \mathrm{kg} / \mathrm{min})$. To counteract this effect, desmopressin $(4 \mu \mathrm{g})$ was given intramuscularly daily during treatment and a minimum daily intake of 3 litres of fluid was ensured. Haemoglobin and serum electrolyte levels were estimated daily, and blood was transfused if the haemoglobin fell below $11 \mathrm{~g} / \mathrm{dl}$.

\section{Measurement of cerebral blood flow}

The two minute slope inhalation method for the measurement of cerebral blood flow was used, according to the technique of Wyper et al. ${ }^{4}$ The method provided a noninvasive assessment of hemisphere cerebral blood flow, which was repeated after reducing the dose of dopamine to the lowest level that could be tolerated safely by the patients. Paired parieto-temporal collimated external detectors were used, providing a simultaneous measurement of cerebral blood flow in each hemisphere. Corrections were applied to minimise detector "cross talk". The 
Table 1 Cerebral blood flow ( $\mathrm{ml} / 100 \mathrm{~g} / \mathrm{min})$ and mean blood pressure (MBP) ( $\mathrm{mm} \mathrm{Hg}$ ) while on dopamine, and after reduction in dosage or withdrawal of dopamine

\begin{tabular}{llllll}
\hline & \multicolumn{2}{c}{ On dopamine } & & \multicolumn{2}{c}{ Offlmin dopamine } \\
\cline { 2 - 3 } \cline { 5 - 6 } & $C B F$ & $M B P$ & & $C B F$ & $M B P$ \\
\hline Ischaemic hemisphere & $34 \pm 2$ & $113 \pm 3$ & $27 \pm 2^{*}$ & $85 \pm 6^{*}$
\end{tabular}
Contralateral hemisphere $38 \pm 4 \quad 113 \pm 3 \quad 32 \pm 4^{*} 85 \pm 6^{*}$

("indicates a significant difference between mean values on and off/min dopamine).

theory of cerebral blood flow measurement using inert diffusable tracers (133 xenon) with this apparatus has been described in detail. ${ }^{5}$ A spirometer with open and closed circuit systems was employed, into which a mixture of 133 xenon and air was introduced, to give a specific activity of approximately $1.0 \mathrm{mCi} /$ litre. A CO2 absorber system was incorporated in the closed circuit. End-tidal $\mathrm{CO} 2$ and 133 xenon concentrations were measured continuously, using a capnograph and a scintillation counter. After an initial acclimatisation period while breathing on the open circuit, and once the end-tidal $\mathrm{CO} 2$ had become steady, a background count was measured, and the patient was switched to the closed circuit. The 133 xenon and air mixture was breathed for two minutes and then the spirometer was switched back to open circuit. After a 30 second lag phase, so that the patient began breathing fresh air again, the clearance of 133 xenon from the head was measured using the two detectors. Calculation of clearance rates, and thus cerebral blood flow, was performed using a three dimensional nomogram developed for this purpose. ${ }^{6}$ The capnograph was calibrated against reference gases. Similar cerebral blood flow estimations were made in normal volunteers and an age-matched flow value was calculated from the linear regression formula that we have previously reported. 7 The rate of dopamine infusion was reduced using an infusion pump with a rate controller, while mean blood pressure was measured and clinical examination was recorded. If focal signs appeared, or if there was deterioration in level of consciousness, then the dosage was immediately increased and cerebral blood flow was measured at the lowest rate of infusion that was possible with safety. If no deterioration occurred, then the dose was reduced further or stopped, and cerebral blood flow was measured. If subsequent deterioration occurred, then dopamine treatment was reinstituted and the withdrawal test was repeated at a later stage.

Statistics Mean cerebral blood flow values were compared with Student's paired $t$ tests. The $2 / 2$ table was analysed with Fisher's exact test.

\section{Results}

The age of the eight patients in whom cerebral blood flow was measured ranged from 22 to 67 years with the average 46.6 years. Cerebral blood flow was measured on three different days during treatment with dopamine infusion in three patients, on 2 days in one patient, and in the remaining four patients cerebral blood flow was measured on 1 day only. Dopamine was continued for 3 to 12 days. The change in mean blood pressure during dopamine withdrawal was from $113( \pm 3.4) \mathrm{mm} \mathrm{Hg}$ to 85 $( \pm 5 \cdot 8) \mathrm{mm} \mathrm{Hg}$ (table 1). Resting cerebral blood flow in the age-matched control group was $40 \pm 4$ $\mathrm{ml} / 100 \mathrm{~g} / \mathrm{min}$. The initial mean cerebral blood flow on the first day that the dopamine withdrawal test was performed was $34.1 \pm 1.7 \mathrm{ml} / 100 \mathrm{~g} / \mathrm{min}$, in the damaged hemisphere and $38.3 \pm 3.7 \mathrm{ml} / 100 \mathrm{~g} / \mathrm{min}$ in the undamaged hemisphere (table 1). After with drawal, or on the lowest safe dosage of dopamine mean cerebral blood flow in the damaged hemio sphere was $27.1 \pm 1.7 \mathrm{ml} / 100 \mathrm{~g} / \mathrm{min}$ and in the undamaged hemisphere was $31.5 \pm 3.9 \mathrm{ml} / 100 \mathrm{~g}$ min. The differences between the mean cerebrad blood flow values at the highest and lowest dosages of dopamine were significant $(p<0.05)$ in both the damaged and the undamaged hemispheres (table 1). Where patients deteriorated, dopamine therapy was resumed, and the withdrawal test was repeated at a later stage. This occurred in four patients, result-

Table 2 Clinical details of the patients and relationship of deterioration to change in cerebral blood flow

\begin{tabular}{|c|c|c|c|c|c|c|c|}
\hline Case No & $\begin{array}{l}\text { Days operation } \\
\text { post bleed }\end{array}$ & Site of aneurysm & Age (yr) & $\begin{array}{l}\text { Onset (days) of first } \\
\text { deficit post/op }\end{array}$ & Day/dopamine & $\begin{array}{l}\text { \% change } \\
\text { of } C B F\end{array}$ & Deterioration \\
\hline 1 & 4 & P. Com. & 46 & 2 & $\begin{array}{l}5 \\
7 \\
9\end{array}$ & $\begin{array}{l}-34 \\
-25 \\
-39\end{array}$ & $\begin{array}{l}+ \\
+ \\
-\end{array}$ \\
\hline 2 & 2 & A. Com. & 67 & 3 & $\begin{array}{r}3 \\
12\end{array}$ & $\begin{array}{l}-26 \\
-13\end{array}$ & $\begin{array}{l}+ \\
-\end{array}$ \\
\hline $\begin{array}{l}3 \\
4\end{array}$ & $\begin{array}{l}5 \\
7\end{array}$ & $\begin{array}{l}\text { MCA } \\
\text { C. Bif. }\end{array}$ & $\begin{array}{l}54 \\
31\end{array}$ & $\begin{array}{l}3 \\
2\end{array}$ & $\begin{array}{r}3 \\
6 \\
7 \\
10\end{array}$ & $\begin{array}{l}-22 \\
-47 \\
-39 \\
-36\end{array}$ & $\begin{array}{l}\overline{+} \\
+ \\
+\end{array}$ \\
\hline $\begin{array}{l}5 \\
6 \\
7\end{array}$ & $\begin{array}{l}2 \\
4 \\
4\end{array}$ & $\begin{array}{l}\text { P. Com. } \\
\text { P. Com. } \\
\text { A. Com. }\end{array}$ & $\begin{array}{l}22 \\
51 \\
23\end{array}$ & $\begin{array}{l}2 \\
6 \\
1\end{array}$ & $\begin{array}{l}3 \\
2 \\
6 \\
7 \\
9\end{array}$ & $\begin{array}{r}-16 \\
-9 \\
-31 \\
-36 \\
-14\end{array}$ & $\begin{array}{l}- \\
\overline{+} \\
+ \\
-\end{array}$ \\
\hline 8 & 4 & $\mathrm{MCA}+\mathrm{A}$. Chor & 31 & 2 & 3 & -17 & - \\
\hline
\end{tabular}

The maximum percentage fall in cerebral blood flow (\% dCBF) in either hemisphere on each occasion when CBF was measured, the number of days after starting the dopamine infusion (day/dopamine) and the occurrence of deterioration. $(+)$. 
Table 3 Relationship between maximum percentage fall in cerebral blood flow in either hemisphere to subsequent neurological deterioration

\begin{tabular}{lll}
\hline & Deterioration & No deterioration \\
\hline Percentage fall $=$ or $>25 \%$ & 7 & 2 \\
Percentage $<25 \%$ & 0 & 6 \\
\hline
\end{tabular}

$p=0.006$ (Fisher's exact test).

ing in 15 such withdrawal tests (table 2). There was no episode of deterioration when the maximum fall in cerebral blood flow that followed reduction in dopamine was less than $25 \%$ of the initial value on either side (table 3 ). By contrast, on only two of nine occasions when cerebral blood flow fell by $25 \%$ or more was withdrawal of dopamine accomplished without deterioration. In these two instances dopamine had been administered for nine and ten days. This difference was very significant $(p=$ 0.006 ). All eight patients were neurologically normal at the time of discharge. Follow-up of more than one year has confirmed that all patients have made a good recovery.

\section{Discussion}

This study focused on the use of cerebral blood flow measurement to test when it is safe to withdraw hypertensive treatment from patients with delayed cerebral ischaemia following aneurysm surgery. It has not set out to evaluate the use of dopamine, or hypertensive treatment in general, nor does it indicate which patients are most likely to benefit from this form of treatment, because clearly there are many other possible causes of deterioration following aneurysm surgery. Dopamine is a useful hypertensive agent in this situation because it has a direct cerebral vasodilator effect. ${ }^{8}$

Deterioration may result from a variety of mechanisms during the postoperative period. Clinically ${ }^{9}$ and experimentally ${ }^{10-12}$ there is evidence that for several days after subarachnoid haemorrhage there is an increased sensitivity to vasoactive substances, and that at this time cerebral perfusion is passively pressure dependent. The clinical diagnosis of delayed cerebral ischaemia is associated with reduced cerebral blood flow, and the failure of a large variety of "antivasospastic" therapeutic regimens $^{1}$ has led to the utilisation of increases in CPP as a therapeutic alternative. ${ }^{3}$ Hypertensive treatment was first reported by Denny-Brown in $1951^{13}$ in the treatment of patients with cerebral ischaemia, and Farhat and Schneider ${ }^{14}$ subsequently reported hypertensive treatment in patients with cerebrovascular insufficiency. They reported prompt reversal of neurological symptoms by increasing the blood pressure with pressor agents. Wise et al ${ }^{15}$ also reported improvement of symptoms from brain ischaemia with vasopressor drugs. Kosnik and Hunt $^{16}$ were the first to report successful reversal of delayed cerebral ischaemia with noradrenalineinduced hypertension following surgery for intracranial aneurysms in 1976. Since then several authors have reported successful responses to hypertensive treatment in patients with postoperative delayed cerebral ischaemia. ${ }^{2317-20}$ Nevertheless it can be difficult to decide when and how rapidly to withdraw hypertensive treatment. Often the patient has become dependent upon the pressor agent, and even gradual withdrawal leads to a fall in blood pressure back to normal or even hypotensive levels, in some cases with subsequent clinical deterioration. Using deterioration as a criterion is therefore unsatisfactory, because it may develop only after a delay, and also because there is the risk that it may not be reversible. In order to discover if we could avoid subjecting patients to premature trials of dopamine withdrawal, we have measured cerebral blood flow while on dopamine treatment and then again immediately after the dosage was reduced or stopped altogether. Our studies in these eight patients have shown that while on dopamine and with elevated blood pressure, cerebral blood flow returned towards normal (although still below the normal value especially in the ischaemic hemisphere). Withdrawal of the dopamine resulted in a fall in mean blood pressure to normal levels (mean value $85 \mathrm{~mm} \mathrm{Hg}$ ) and a significant fall in cerebral blood flow. When the cerebral blood flow changes were compared with the subsequent clinical course, it became clear that a reduction of $25 \%$ or more was frequently followed by deterioration, but that a reduction of less than $25 \%$ was not. This watershed for reduced cerebral blood flow corresponds with the figure which Leech and Miller have previously used to predict which patients could safely undergo carotid ligation. ${ }^{21}$ The concept of such a "stress" test in cerebral blood flow measurement was initially referred to by Jennett $e t a^{22}$ who also found that a $25 \%$ threshold was useful for clinical decision making.

These findings in our eight patients should be regarded as preliminary, and we suggest that in patients whose reduction in blood flow is less than $25 \%$ it is safe to withdraw dopamine treatment. Further experience with this withdrawal test in a larger group of patients should determine whether these criteria are correct or not.

Mr S Dharker was supported by the British Council. Our thanks go to Miss Anne Semple for preparing the manuscipt. 


\section{References}

' Wilkins RH. Attempted prevention or treatment of intracranial arterial spasm: a survey. Neurosurgery 1980; 6: 198-210.

${ }^{2}$ Giannotta SL, McGillicuddy E, Kindt GW. Diagnosis and treatment of post operative cerebral vasospasm. Surg Neurol 1977;8:286-90.

${ }^{3}$ Kassell NF, Peerless SJ, Durward QJ, Beck DW, Drake CG, Adams HP. Treatment of ischaemic deficits from vasospasm with intravascular volume expansion and induced arterial hypertension. Neurosurgery 1982; 11:337-43.

${ }^{4}$ Wyper DJ, Lennox GA, Rowan JO. Two minute slope inhalation technique for cerebral blood flow measurement in man. I: Method. J Neurol Neurosurg Psychiatry 1976;39:141-6.

5 Wyper DJ, Lennox GA, Rowan JO. Two minute slope inhalation technique for cerebral blood flow measurement in man. II: Clinical Appraisal. J Neurol Neurosurg Psychiatry 1976;39:147-51.

${ }^{6}$ Wyper DJ, Rowan JO. The construction and use of nomograms for cerebral blood flow calculation using a 133 Xenon inhalation technique. Phys Med Biol 1976;21:406-13.

${ }^{7}$ Bullock R, Mendelow AD, Bone I, Patterson J, McLeod WN, Allardice G. Cerebral blood flow and $\mathrm{CO} 2$ responsiveness as an indicator of collateral reserve capacity in patients with carotid arterial disease. $\mathrm{Br} \mathrm{J}$ Surg 1985;72:348-51.

${ }^{8}$ Tuor UI. Effect of moderate hypertension induced by Dopamine or Noradrenaline on local cerebral blood flow in the rat. $J$ Physiol (Lond) 1985;360:28.

' Yamakami I, Siobe K, Yamaura A, Nakamura T, Makino H. Vasospasm and regional cerebral blood flow (rCBF) in patients with ruptured intracranial aneurysm: Serial rCBF Studies with the Xenon 133 inhalation method. Neurosurgery 1983;13:394-401.

${ }^{10}$ Boisvert DP, Overton TR, Weir B, Grace MG. Cerebral arterial responses to induced hypertension following subarachnoid haemorrhage in the monkey. $J$ Neurosurg 1978;49:75-83.

"Mendelow AD, McCalden TA, Hattingh J, Coull A,
Rosendorff C, Eidelman BH. Cerebrovascular reactivity and metabolism after subarachnoid haemorrhage in baboons. Stroke 1981;12:58-65.

12 Pickard JD, Perry S. Spectrum of altered reactivity of isolated cerebral arteries following subarachnoid haemorrhage: response to potassium, $\mathrm{pH}$, noradrenaline, 5-hydroxytryptamine, and sodium loading. $J$ Cerebral Blood Flow Metab 1984;4:599-609.

${ }^{13}$ Denny-Brown D. The treatment of recurrent cerebrovascular symptoms and the question of "vasospasm". Med Clin North Am 1951;35:1457-74.

${ }^{14}$ Farhat SM, Schneider RC. Observations on the effect of systemic blood pressure on intracranial circulation in patients with cerebrovascular insufficiency. $J$ Neurosurg 1967; 27:441-5.

15 Wise G, Sutter R, Burkholder J. The treatment of brain ischaemia with vaso pressor drugs. Stroke 1972; 3: $135-42$.

${ }^{16}$ Kosnik EJ, Hunt WE. Post operative hypertension in the management of patients with intracranial arterial aneurysms. J Neurosurg 1976;45:148-54.

17 Boullin DJ, Adams CBT, Mohan J, Green AR, Hunt TM, du Boulay GH, Rogers AT. Effects of intracranial Dopamine perfusion: behavioural arousal and reversal of cerebral arterial spasm following surgery for clipping of ruptured cerebral aneurysms. Proc $R$ Soc Med 1977; 70:55-70.

${ }^{18}$ Symon L. Management of aneurysmal subarachnoid haemorrhage. Adv Neurol 1979;25:301-4.

${ }^{14}$ Hope DT, Branston NM, Symon L. Restoration of U neurological function with induced hypertension in acute experimental cerebral ischaemia. Acta Neuro $\mathbb{R}$ Scand (suppl 56) 1977;64:506-7.

${ }^{20}$ Brown FD, Hanlon K, Mullan S. Treatment of aneurysmal hemiplegia with Dopamine and Mannitol. Neurosurg 1978;49:525-9.

${ }^{21}$ Leech PJ, Miller JD, Fitch W, Barker J. Cerebral blooø flow, internal carotid artery pressure, and EEG as guide to the safety of carotid ligation. J Neurol Neurosurg Psychiatry 1974;37:854-62.

22 Jennett WB, Harper AM, Gillespie FC. Measurement of regional cerebral blood-flow during carotid ligation. Lancet 1966;2:1162-3. 